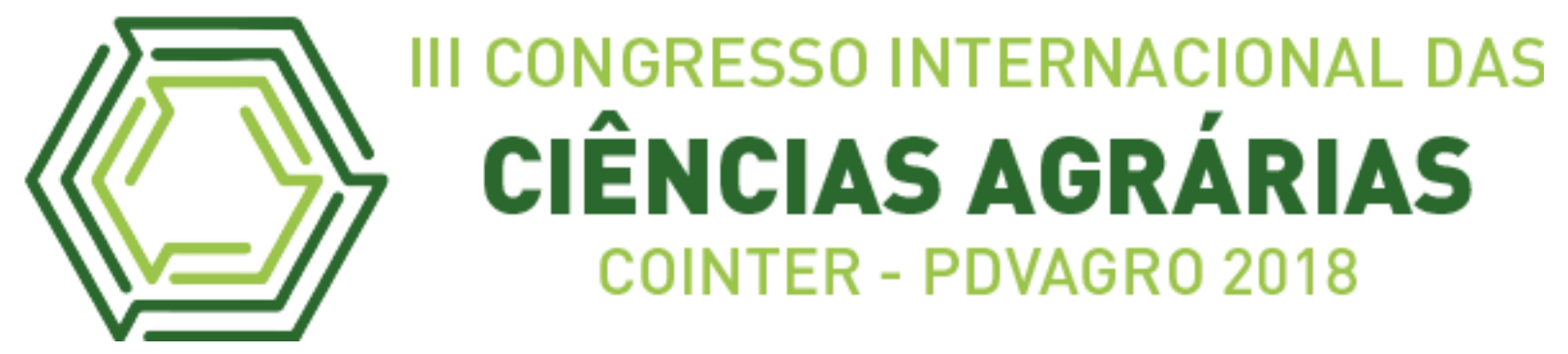

\title{
DIA DE CAMPO: PRODUÇÃO DE FORRAGENS ALTERNATIVAS A PARTIR DE PLANTAÇÃO DE XERÓFITAS NO SEMIÁRIDO
}

\section{FIELD DAY: A REPORT OF EXPERIENCE FROM XEROPHY SPECIES PLANTING IN THE SEMIARID}

\author{
Apresentação: Relato de Experiência \\ Maria Alaíne da Cunha Lima ${ }^{1}$; Marília Fernada dos Santos ${ }^{2}$; Liliane Sabino dos \\ Santos ${ }^{3}$; Gislayne Kayne Gomes da Cruz ${ }^{4}$; José Alif Rozeno da Silva ${ }^{5}$ Frederico Campos \\ Pereira $^{6}$
}

DOI: https://doi.org/10.31692/2526-7701.IIICOINTERPDVAGRO.2018.00729

\section{Introdução}

As cactáceas são plantas com aspectos anatômicos, ecológicos e fisiológicas peculiares, a família das Cactaceae ao longo dos séculos se adaptaram ao clima seco. As espécies de cactáceas são em geral xerófitas, suculentas, perenes e adaptadas às regiões semiáridas. Os cactos possuem hábitos diversos: arbóreo, arbustivo, subarbustivo, trepador, epífito ou geófito; apresentam raiz fibrosa ou tuberosa. O caule pode assumir formas colunares, cilíndricas, globulares, aladas ou achatadas, sendo frequentemente segmentado e, na maioria das vezes, sem folhas típicas, geralmente modificadas em espinhos (ZAPPI et al., 2008).

A Caatinga é o bioma exclusivo do Brasil sendo presente em grande parte do Nordeste com um ecossistema diversificado, com planas adaptadas ao semiárido. O nome "caatinga" é de origem Tupi-Guarani e significa floresta branca, que certamente caracteriza bem o aspecto da vegetação na estação seca, quando as folhas caem (PRADO, 2003).

Segundo Oliveira (1996) relatou que, em razão das incertezas climáticas e do fenômeno das secas periódicas que ocorrem na região semi-árida do Nordeste brasileiro, as cactáceas representam uma fonte de suprimento de água e uma alternativa alimentar para os

\footnotetext{
${ }^{1}$ Tecnólogo em Agroecologia , IFPB, alainelima1@gmail.com

${ }^{2}$ Tecnólogo em Agroecologia , IFPB, mariliaagro505@gmail.com

${ }^{3}$ Tecnólogo em Agroecologia , IFPB, lillyane43@gmail.com

${ }^{4}$ Tecnólogo em Agroecologia , IFPB, gyh.kayne@gmail.com

5 Tecnólogo em Agroecologia , IFPB, aliffrozeno.agro@gmail.com

${ }^{6}$ Professor Agroecologia, IFPB, fredcampos2000@yahoo.com
} 
animais.

Esse relato de experiencia visa descrever passo a passo uma experiencia de um dia de campo promovida pelo NEA (Núcleo de Estudos em Agroecologia). O dia de campo teve como objetivo quantificar a produção de massa verde de espécies xerófilas em áreas degradadas na fazenda gavião,

\section{Relato de Experiência}

O dia de campo foi promovido pelo NEA (Núcleo de Estudos em Agroecologia), que reuniu diversos pesquisadores e extensionistas de várias instituições, contou com presença de agricultores, prefeitos e secretários da região, além da participação dos estudantes do curso de agroecologia do Instituto Federal da Paraíba campus Picuí, integrantes do NEA.

O experimento foi montado no ano de 2011 em três áreas antropizadas, descritas a seguir: a) Uma degradada por sobrepastejo ovinos e caprinos; b) outra por Lavouras anuais e sobrepastejo bovino e c) outra por Agricultura (monocultivo de algodão e sisal), todas inseridas no município de Picuí - PB. Picuí apresenta uma área de 66.646,68 ha. No dia de campo essas áreas ficaram divididas por quatro estações A primeira com três anos de plantio continha várias cactáceas,porém foram colhidas nessa estação o Mandacaru sem espinhos (Cereus hildmanhianus), o Xique-xique (Pilosocereus gounellei) e a Palma-de-Espinho (Opuntia dillenii).

Na segunda estação tinha as plantações com sete anos de idade, onde se procedeu da mesma maneira. Foram escolhidas três plantas de maneira aleatória na qual foi realizada o corte e após a pesagem, por linha em cada parcela para chegar o resultado da média do peso por planta e da multiplicação pela densidade de plantio. A terceira estação era a de processamento das cactáceas e do balanceamento da ração adicionando-se fibras, podendo ser capins e silagem de plantas nativas da Caatinga como a maniçoba por exemplo.

O cálculo que resultou o valor final de biomassa foi um cálculo de média simples. A retirada da amostragem foi no dia 15 de junho de 2018, que foi retirada as brotações laterais de três plantas por parcela, pesadas e retirada as médias por plantas. Após isso, realizou-se a projeção da biomassa por um hectare, multiplicando-se pelo número de plantas escolhidas, através do espaçamento do plantio.

Para a avaliação do experimento utilizou-se o método diretos de avaliação, 
procedendo-se o corte das hastes que botaram da principal ao longo do tempo, usando-se de instrumentos de corte como faca e facões. A pesagem do material úmido (matéria verde), ou seja, das brotações destacadas da planta principal se deu por meio da destruição parcial das partes que brotaram ao longo dos 2.555 dias após o plantio (DAP), das espécies de cactáceas (mandacaru, xique-xique, palma com espinho e sem espinho). As hastes foram pesadas em balança eletrônica digital e os dados armazenados em planilhas do programa Excel, a média dos pesos foi dado em quilogramas.

Imagem 1 e 2 : Corte das Plantas na Primeira Estação. Fonte: Própria

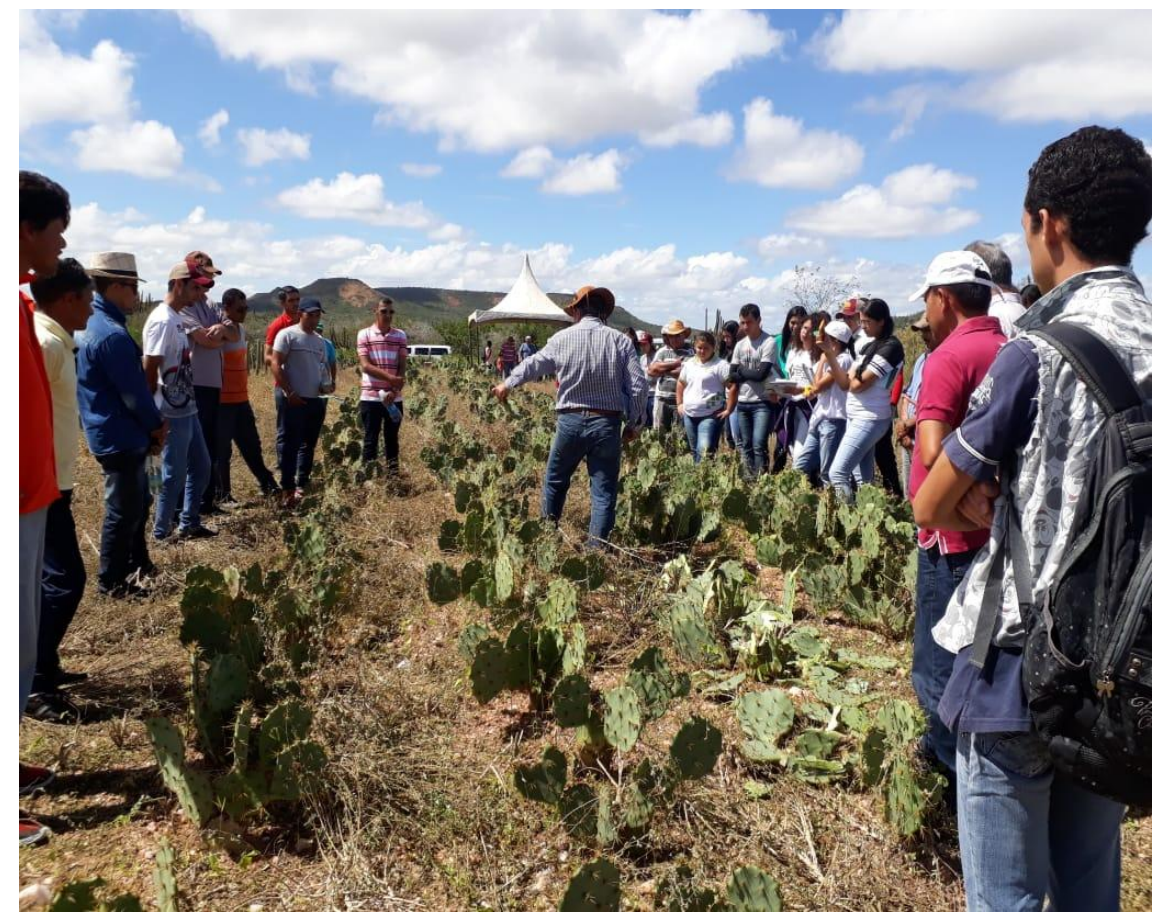




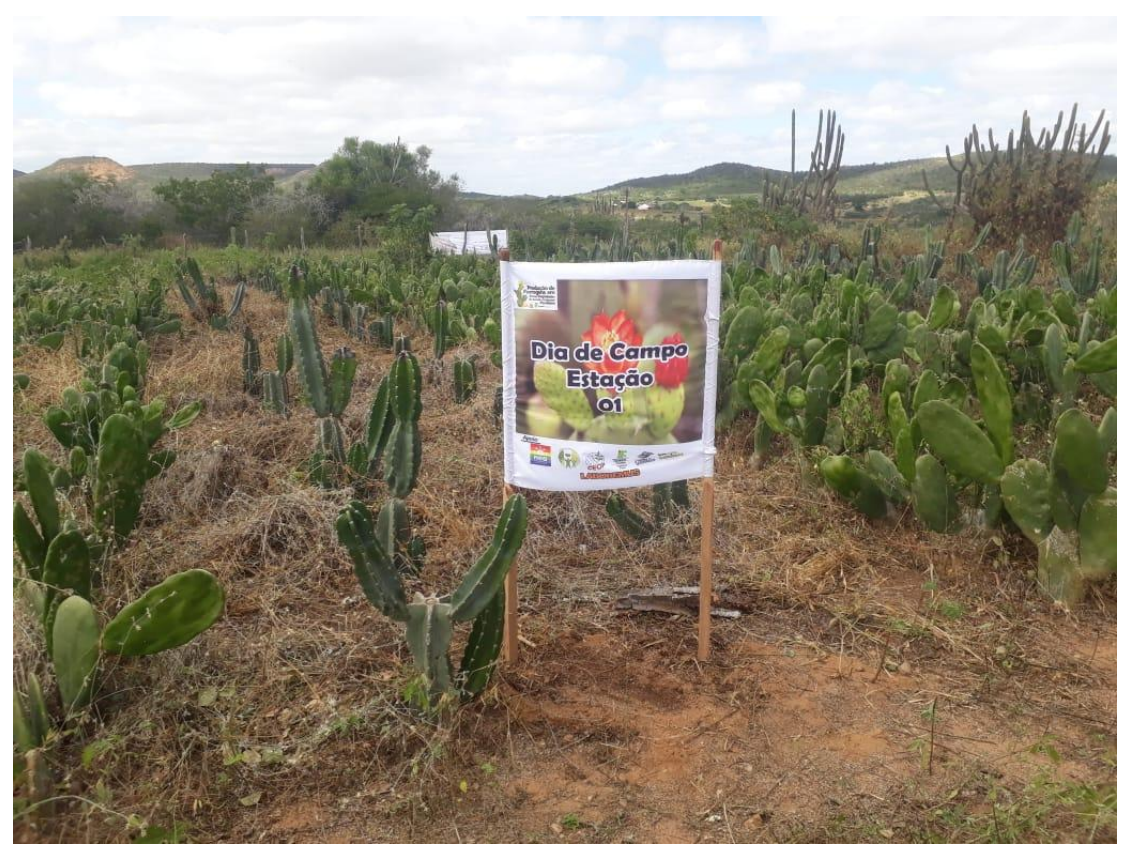

O dia de campo foi essencial para alunos, agricultores e pesquisadores em geral, mostrando e comprovando o desenvolvimento das cactáceas, além do manejo adequado em áreas degradadas, bem como a importância de repor as espécies que é retirada de forma descontrolada do ambiente no período da seca. Essas espécies são o único meio encontrado para suprir a alimentação animal, já que a mesma se encontra com facilidade no campo, mas nenhuma medida é tomada para repor as espécies. Promover o conhecimento através de atividade desse cunho é de suma importância, pois é fundamental para que haja um olhar direcionado para saídas viáveis que gerem renda e melhorem a qualidade de vida do seridoense e/ou sertanejo á medida que se valorizem espécies que possam agregar valor e oportunizar uma inclusão social com o desenvolvimento e utilização de forma adequada destas espécies para o auto-sustento das famílias do campo.

\section{Considerações}

As espécies plantadas obtiveram uma boa produção de biomassa verde mesmo em área degradada, as plantas em estudo se desenvolveram e sobreviveram, mesmo em um local que apresentava área degrada e com ambiente desfavoráveis, como índices baixos de chuvas e temperaturas elevadas. Por tanto, mostra- se que as espécies são indicadas para serem utilizadas em áreas em perfil de degradação, além de fornecer alimentação animal no período de longa estiagem.

\section{Referências}


ZAPPI, D. C.; TAYLOR, N. 2008. Diversidade e endemismo das Cactaceae na Cadeia do Espinhaço. Megadiversidade. Volume 4 (No 1-2). 111-116.

PRADO, D. E. As Caatingas da América do Sul. In.: LEAL, I. R. \& TABARELLI, M. (Eds.) Ecologia e Conservação da Caatinga. Editora Universitária: UFPE. 2003.

OLIVEIRA, E. R. Alternativas de alimentação para pecuária do semi-árido nordestino. In: SIMPÓSIO NORDESTINO DE ALIMENTACÃO DE RUMINANTES, 6., 1996, Natal. Anais... Natal: EMPARN, 1996. p.127-147. 